\title{
A climate-based model for tick life cycle: an infinite system of differential equation approach.
}

\author{
Cyrine Chenaoui ${ }^{\mathrm{a}, *}$, Slimane Ben Miled $^{\mathrm{a}}$, Mamadou Sadio Ndongo ${ }^{\mathrm{b}, \mathrm{d}}$, Papa \\ Ibrahima Ndiaye ${ }^{b, c, d}$, Mourad Rekik ${ }^{\mathrm{f}}$, Mohamed Aziz Darghouth ${ }^{\mathrm{e}}$ \\ ${ }^{a}$ Institut Pasteur de Tunis, Université de Tunis el Manar, 1002 Tunis, Belvédère, Tunisia \\ ${ }^{b}$ Laboratoire d'Informatique et de Mathématiques Appliquées, UFR SATIC, \\ Université Alioune Diop, BP 30 Bambey, Senegal \\ ${ }^{c}$ Centre d'Excellence Africain Agir "Environnement, Santé, Sociétés", \\ Université Cheikh Anta Diop, BP 5005, Dakar-Fann, Senegal \\ ${ }^{d}$ Laboratoire d'Analyse Numérique et d'Informatique, UMI 209 UMMISCO, \\ Université Gaston Berger BP 234, Saint-Louis, Senegal \\ ${ }^{e}$ Ecole Nationale de Médecine Vétérinaire, \\ Université de la Manouba, 2020 Sidi Thabet, Tunisia \\ ${ }^{f}$ International Center for Agricultural Research in the Dry Areas (ICARDA), Amman, Jordan
}

\begin{abstract}
The distribution of ticks is essentially determined by the presence of climatic conditions and ecological contexts suitable for their survival and development.

We have developed a general tick biology model to study the major trends due to climate change on tick population dynamics under different climate conditions.

We build a model that explicitly takes into account stage into each physiological state through a system of infinite differential equations where tick population density are structured on an infinite discrete set. We suppose that intrastage development process is temperature dependent (Arrhenius temperatures function) and that larvae hatching and adult mortality are temperature and precipitations dependent.

We analysed mathematically the model and have explicit the $R_{0}$ of the tick population. Therefore, we performed a numerical analysis of the model under three different climate conditions (tropical, Mediterranean and subarctic climates) over the short term using climatic data from 1995 to 2005, as well as long-term simulations from 1902 to 2005.
\end{abstract}

\footnotetext{
* Corresponding author

Email addresses: cyrine.chenaoui@gmail.com (Cyrine Chenaoui), slimane.benmiled@fst.utm.tn (Slimane Ben Miled), madsadio765@gmail.com (Mamadou Sadio Ndongo), papaibra.ndiaye@uadb.edu.sn (Papa Ibrahima Ndiaye), m.rekik@cgiar.org (Mourad Rekik), mohamedaziz.darghouth@enmv.uma.tn (Mohamed Aziz Darghouth)
} 


\section{Introduction}

There are up-to-date more than 900 ticks species showing specific distributions over the world, and only 25 of these species are representing major threats to humans and animals, essentially through the transmission of pathogens[21].

5 Indeed, amongst all the hematophagus vectors, ticks are those transmitting the highest range of pathogenic, bacteria, parasites and viruses [35], causing important human and animal diseases such as for instance tick-borne encephalitis in humans and malignant theileriosis in livestock [3]. The distribution of ticks is essentially determined by the presence of climatic conditions and ecological

10 contexts suitable for their survival and development, including the presence of the required hosts for the feeding of immature and adult stages. The distribution and population density of tick species as well as the relative importance of the transmitted tick-borne pathogens for humans and animals depend greatly on the suitability of the eco-climatic conditions regarding the tick biological 15 requirements.

Tick biology is complex and exhibit a high level of biological polymorphism observed between the different tick genera and even between the different species within a given genus. For instance, in the Hyalomma genus, some species are relatively less adapted to drought and high temperature, like for instance $H$.

20 lusitanicum and to a lesser extent $H$. scupense, comparatively to $H$. dromedarii and $H$. anatolicum $[38,8]$. This high polymorphism is exacerbated by the complexity of the interaction between the ticks, their hosts, and the pathogens they transmit. Accordingly, understanding and predicting the mechanisms leading to a determined phenology is quite impossible. The ongoing dynamic

25 of climate change is bringing an additional layer of variability that imposes to adopt a proactive attitude to those concerned by on the control of the major ticks and ticks borne diseases (TBD) in humans and animals. In this changing context, where working as usual is certainly not the solution, predicting the size of tick populations and anticipating the impact of different control actions so remain difficult. However, modeling represents a powerful alternative that could overcome these difficulties, offering then valuable decision aid data that bring a rational basis for deploying proactive measures against ticks and TBD.

The object of the present work is to develop a general tick biology model for analysing the major effects of climate change on the evolution of tick population

35 dynamic in different climate conditions (tropical, Mediterranean and subarctic climates).

Models for tick population dynamics often describe in a discrete way the various stages of ticks development from egg-larva-nymph-adult (e.g. [9]), whether the ticks are attached to hosts [20], and if disease is part of the model, whether 40 the ticks themselves are infected $[19,10]$. For instance, $[31,24,22]$ and more recently Lou and $\mathrm{Wu}[17]$ proposed a model where ticks are subdivided in the three stages (larvae, nymphs and adults) with stage progression only through a blood meal on a vertebrate host (two types of which are considered in the model).

45 Empirical studies confirm that the developmental and questing activity of 
ticks are regulated by the climate $[16,27,28,32,5,26]$. In addition, seasonal variations are one of the major factors in the transition from one stage to another [6]. Given the critical impact of climate change on tick life cycles, several models has been constructed $[7,31,25,2,4]$.

50 [31] proposed a model that considers diapause and density-dependent regulation of nymphs and adult stages, as well as temperature-dependent rates of development and egg production, and density-independent but climate-dependent mortality rates for both larval and adult stages. Their model accurately predicts both the seasonality and the annual spectrum of variation in life stages density

${ }_{55}$ tick species Rhipicephalus appendiculatus. More recently, [11] developed an age-structured model to examine the effect of shifts in average temperature on seasonal activity of ticks and on interstadial development.

Also, Ogden et al. [25] developed a dynamic population model of Ixodes scapularis, where tick development rates are temperature-dependent time delays, ${ }_{60}$ calculated using mean monthly normal temperature data and then applied to forecast theoretically the physical boundaries for Ixodes scapularis establishment in Canada and host-finding success.

To predict the possible consequences of climate change on ticks' dynamics, a more extensive understanding of the relative contributions of temperature65 dependent mechanisms is crucial. As an extension of previous work [25], we propose in this study to model on a temperature-dependent basis the dynamics of tick populations using a system of finite non-autonomous differential equations where tick population density are structured on a finite discrete set. Temperature is the most extensively analysed climatic factor for establishing the effect of the 70 phenomenon of climate change allowing therefore to extend its application for exploring the putative effects of changing climatic conditions on tick dynamics using the temperature-dependent model developed in the present work.

We performed a numerical analysis of the model under the Mediterranean climate of north-east Tunisia, focusing on the endemic tick species $H$. scupense.

75 We also extended our analysis to two other climates, namely, a tropical climate in Senegal with the tick Amblyomma variegatum, and a subarctic climate in Canada with the tick Ixodes cookei. In order to evaluate the predictive functionality of the model we also run, in each of the three climatic contexts with the corresponding endemic tick species, a simulation using climatic data to assess the short-term

so trends during the decade $1995-2005$ and the long term trends over one century from 1902 until 2005.

In section 2, we describe the mathematical model. Later in section 3 we exhibit numerical result respectively in constant and fluctuating temperature. Finally, in 4 an analysis of results is presented, and the limits of our model are 85 discussed.

\section{Model description}

Under the Mediterranean climate of North Africa [8], H.scupense adults take a blood meal during the summer. Females detach from the animal, layout eggs 


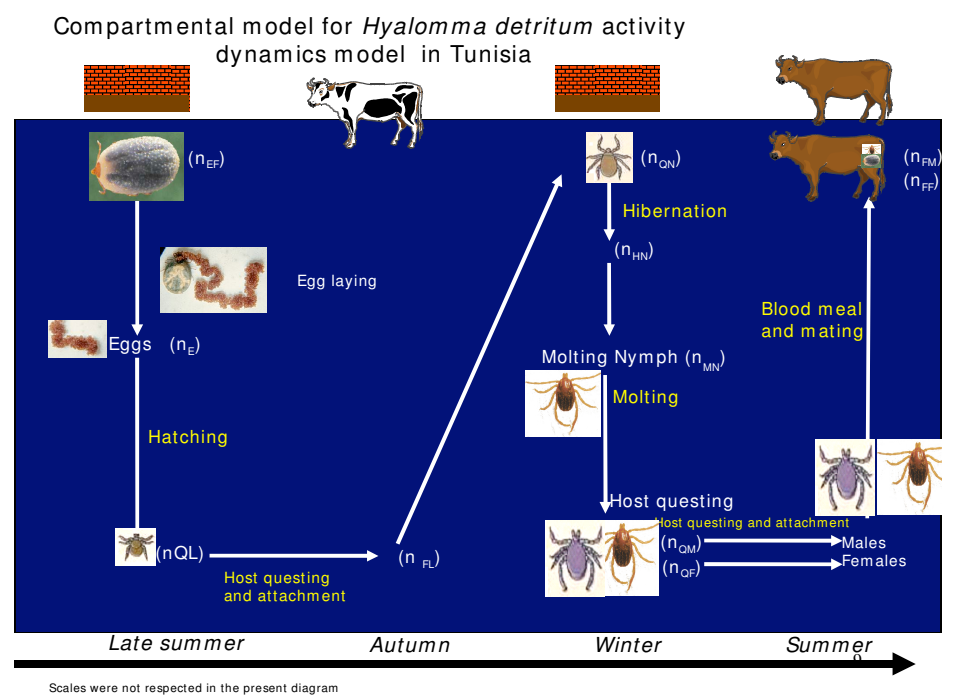

Figure 1: Different states of the tick

and die. The larvae start questing for a host for feeding and then moult into 90 nymphs. The nymphs, also, take one blood meal and detach. Immature ticks are observed on animals during the autumn. The engorged nymphs look for a shelter (wall cracks and crevices in the barn) and enter diapause (see figure 1).From the end of the spring to the beginning of summer, the nymphs moult into adults and leave the shelters and start questing for a host.

Thus, the physiological growth inside in stage is a continuous process, which can be approached by a physiologically structured model using Usher's matrix ??. The equation considered in this model is derived from a discrete physiologicalstructured model for a population in which individuals change their stage according to seasonality.

To illustrate the ideas underlying the model, we consider a population divided into four physiological stages, eggs, larvae, nymphs and adults, each one being structured by development stage, $s$. We suppose that $s \in\left\{s_{j} / j \leq p-1\right\}$, with $p$ the stage number and denote for all $i \leq p, e_{i}(t)$ the density of egg, $l_{i}(t)$ the density of larvae, $n_{i}(t)$ the density of nymph and $a_{i}(t)$ the density of adult at time $t$ and in the development state $s_{i}$. Capitals, $E(t), L(t), N(t)$ and $A(t)$, denoted the total population number at time $t$.

Let's note, for every physiological stage $s_{i}$ with $i \leq p$, by $T_{e}^{i}, T_{l}^{i}\left(\right.$ resp. $T_{n}^{i}$ ) the interstate transition rate to the larva, nymph, and adult stages. We denote, $g_{e}^{i}, g_{l}^{i}, g_{n}^{i}$ and $g_{a}^{i}$ the intrastate transition rate corresponding to the development stage denoted for the egg, larva, nymph, and adult. It represents the physiological maturity increasing rate. 


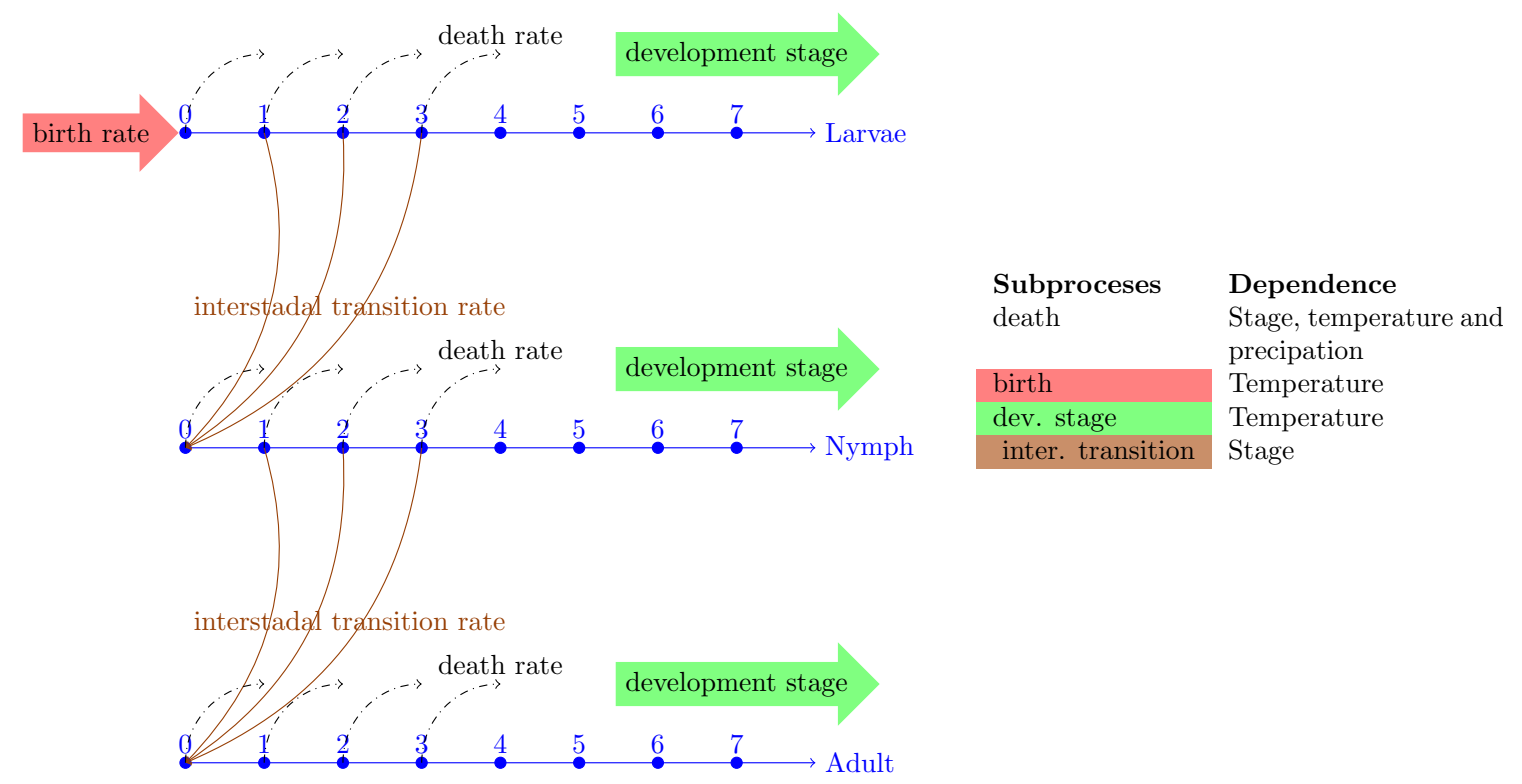

Figure 2: A schematic diagram for the model, identifying the input parameters and the model output (predicted number of ticks at each stage)

We also represent, $\beta^{i}$, the eggs' production rate and $\mu_{e}^{i}, \mu_{l}^{i}, \mu_{n}^{i}$ and $\mu_{a}^{i}$ the death rate of the egg, larva, nymph and adult at stage $s_{i}$.

To simplify the model and as our objective is to study the effect of temperature 115 on the life cycle, we will neglect the effects of density dependencies especially on nymph and larva mortality, as well as on transition rates. It is noted that the effect of density dependence has been discussed at length by different authors $[12,31,20,34,9,33,23]$.

According to the above arguments, the model equations are (see figure 2):

\section{Egg:}

$$
\left\{\begin{aligned}
\frac{d e_{0}(t)}{d t} & =\sum_{i=1}^{p} \beta^{i}(t) a_{i}(t)-\mu_{e}^{0}(t) e_{0}(t)-g_{e}^{0}(t) e_{0}(t) \\
\frac{d e_{i}(t)}{d t} & =-\left(T_{e}^{i}+\mu_{e}^{i}(t)+g_{e}^{i}(t)\right) e_{i}(t)+g_{e}^{i-1}(t) e_{i-1}(t), i \geq 1
\end{aligned}\right.
$$

\section{Larva:}

$$
\left\{\begin{aligned}
\frac{d l_{0}(t)}{d t} & =\sum_{i=1}^{p} T_{e}^{i} e_{i}(t)-\mu_{l}^{0}(t) l_{0}(t)-g_{l}^{0}(t) l_{0}(t) \\
\frac{d l_{i}(t)}{d t} & =-\left(T_{l}^{i}+\mu_{l}^{i}(t)+g_{l}^{i}(t)\right) l_{i}(t)+g_{l}^{i-1}(t) l_{i-1}(t), i \geq 1
\end{aligned}\right.
$$




\section{Nymph:}

$$
\left\{\begin{aligned}
\frac{d n_{0}(t)}{d t} & =\sum_{i=1}^{p} T_{l}^{i} l_{i}(t)-\mu_{n}^{0}(t) n_{0}(t)-g_{n}^{0}(t) n_{0}(t) \\
\frac{d n_{i}(t)}{d t} & =-\left(T_{n}^{i}+\mu_{n}^{i}(t)+g_{n}^{i}(t)\right) n_{i}(t)+g_{n}^{i-1}(t) n_{i-1}(t), i \geq 1
\end{aligned}\right.
$$

Adult:

$$
\left\{\begin{aligned}
\frac{d a_{0}(t)}{d t} & =\sum_{i=1}^{p} T_{n}^{i} n_{i}(t)-\mu_{a}^{0}(t) a_{0}(t)-g_{a}^{0}(t) a_{0}(t) \\
\frac{d a_{i}(t)}{d t} & =-\left(\mu_{a}^{i}(t)+g_{a}^{i}(t)\right) a_{i}(t)+g_{a}^{i-1}(t) a_{i-1}(t), i \geq 1
\end{aligned}\right.
$$

\subsection{Temperature effect}

In endothermic species (e.g. ticks), metabolic rates are governed by biochemical reactions and thus are temperature-dependent. Based on [15], growth, in particular, corresponds to the conversion of absorbed energy to structure and so is temperature-dependent along with other factors, then we could consider the that are inactive at extreme temperatures, metabolic rates are reduced at low and high temperatures.

For simplicity, we suppose that only transitions rates, $\left(g_{j}^{i}\right)_{i \leq n}$, with $j \in$ $\{e, l, n, a\}$ are temperature-dependent, i.e. $g_{j}^{i}=g_{j}(T)$ for all $i \leq n$.However, as we suppose there is density dependence (e.g. no competition for blood meal), we will consider that interstate transition rates, $\left(T_{j}^{i}\right)_{i \leq n}$, with $j \in\{e, l, n, a\}$ depend only on physiological stage, $\left(s_{i}\right)_{i \leq n}$, as following:

$$
T_{j}^{i}=T_{\max }\left(\frac{s_{i}-s_{\min }}{s_{\max }}\right)^{\eta},
$$

with $j \in\{e, l, n\}, \eta \in \mathbb{R}_{+}$a physiological parameter and $T_{\max }$ the maximum transitions rate. We suppose that $s_{\min }$ and $s_{\max }$, the min and max development stage for each physiological stage values are set at 0 and 1 .

We have considered in our model that larva and nymph mortalities are constant in the tolerance temperature range, $\left[T l_{j}^{\mu}, T h_{j}^{\mu}\right]$ for $j=\{e, l, n, a\}$ Randolph [29]. Therefore, let:

$$
\mu_{j}(T)= \begin{cases}\mu_{j}^{*} & \text { if } T \in\left[T l_{j}^{\mu}, T h_{j}^{\mu}\right] \\ \bar{\mu}_{j} & \text { if } T>T h_{j}^{\mu} \\ \underline{\mu}_{j} & \text { if } T<T l_{j}^{\mu}\end{cases}
$$

and

$$
\beta(T)= \begin{cases}\beta^{*} & \text { if } T \in\left[T l^{\beta}, T h^{\beta}\right] \\ 0 & \text { otherwise }\end{cases}
$$

With, $\bar{\mu}_{j}$ and $\underline{\mu}_{j}$ the mean death rate at high and low temperature. 
However, we suppose that egg hatching, larva, and nymph transition rates depend linearly on temperature $T$ :

$$
g_{j}(T)= \begin{cases}g_{j}^{*}+w_{g_{j}}^{T} T & \text { if } T \in\left[T l_{j}^{g}, T h_{j}^{g}\right] \\ \bar{g}_{j} & \text { if } T>T h_{j} \\ \underline{g}_{j} & \text { if } T<T l_{j}\end{cases}
$$

with for all $j=\{e, l, n, a\}, g_{j}^{*}$ and $w_{g_{j}}^{T}$, stand for the temperature effect of the intrastate transition rate (i.e. development rate) in the tolerance temperature 145 range $\left[T l_{j}^{g}, T h_{j}^{g}\right]$. Overline and underline stand, respectively, for mean survival at high and low temperature. See table 1 for the definition of the parameter model.

\section{Numerical results}

We simulate ticks population of eggs, $\left(e_{i}(t)\right)_{i \leq p}$, larvae, $\left(l_{i}(t)\right)_{i \leq p}$, nymphs ${ }_{150}\left(n_{i}(t)\right)_{i \leq p}$ and adults $\left(a_{i}(t)\right)_{i \leq p}$, densities for a finite physiological structure $\left(s_{i}\right)_{i \leq p}(p=100)$, and for three different climate conditions, tropical (Senegal), Mediterranean (Tunisia) and subarctic climates (Canada). We also performed simulations for two distinct periods: a 10-year period and a longer one of more than 100 years. Climate data used in this model are the Climatic Research Unit

1 .

\subsection{Constant temperature simulation}

We simulate the density of larvae, nymphs and adults for $T=24^{\circ} \mathrm{C}$ over a 25 month period. We note that the tick population at this temperature performs a little more than 2 cycles per year (see figures 3 and 4 ). Figure 4 indicates that the larvae are present at varying densities throughout the year at a constant temperature, with two peaks, one in March and the other in September and October. It's important to note that the density of larvae is lowest in the summer (June and July) and winter (December and January). There is a slight overlap 165 between the two stages for nymphs and adults (figure3), with two peaks after the preceding stage's peak.

We then calculated the basic reproduction number $R_{0}$ of the population for $T \in[15,33]^{\circ} \mathrm{C}$. We notice that $R_{0}$ admits a maximum at $22^{\circ} \mathrm{C}$ with a value of 3.4 , then decreases slowly to $T=30^{\circ} \mathrm{C}$ (see figure $5 \mathrm{a}$ ). The sensitivity analysis of the $R_{0}$ (see figure $5 \mathrm{~b}$ ) in relation to the variation with respect to temperature $T$ showed two sensitivity picks, one at $19^{\circ} \mathrm{C}$ and the second at $30.5^{\circ} \mathrm{C}$. These two peaks correspond to the discontinuities of $R_{0}$. Moreover, in the set $[19,30]^{\circ} \mathrm{C}$, $R_{0}$ is almost not sensitive to $T$.

\subsection{Simulations with fluctuating temperature}

175 We performed a numerical analysis of the model under three different climate conditions (tropical, Mediterranean, and subarctic climates) and using climatic 
Table 1: Input parameter values for the population model for the three sites: Canada (CA), Tunisia (TN) and Senegal (SN)

\begin{tabular}{|c|c|c|c|c|c|}
\hline & $e$ & $l$ & $n$ & $a$ & Ref. \\
\hline \multicolumn{6}{|c|}{ Diapause temperature in Celsius, $T l_{j}^{g}$, for the three sites: Canada, Tunisia and Senegal } \\
\hline $\mathrm{CA}$ & 14 & 12 & 4 & 5 & $\begin{array}{l}\text { Unpublished } \\
\text { data }\end{array}$ \\
\hline $\mathrm{TN}$ & 14 & 12 & 4 & 5 & $\begin{array}{l}\text { Unpublished } \\
\text { data }\end{array}$ \\
\hline $\mathrm{CA}$ & 14 & 12 & 4 & 5 & $\begin{array}{l}\text { Unpublished } \\
\text { data }\end{array}$ \\
\hline
\end{tabular}

Commun input parameter values for the three sites: Canada, Tunisia and Senegal

\begin{tabular}{|c|c|c|c|c|c|c|}
\hline$g_{j}^{*}$ & $\begin{array}{l}\text { Mean transition } \\
\text { rate }\end{array}$ & -55 & -87.7692 & -6.87 & -20.07 & $\begin{array}{l}\text { Unpublished } \\
\text { data }\end{array}$ \\
\hline$w_{g_{j}}^{T}$ & $\begin{array}{l}\text { Effect of tempera- } \\
\text { ture, } T \text {, on transi- } \\
\text { tion rate }\end{array}$ & 6.06 & 6.8846 & 6.8846 & 6.8846 & $\begin{array}{l}\text { Unpublished } \\
\text { data }\end{array}$ \\
\hline$\mu_{j}^{*}$ & Mean death rate & 0.0450 & 0.0159 & 0.0114 & 0.0196 & $\begin{array}{l}\text { Unpublished } \\
\text { data }\end{array}$ \\
\hline $\bar{\mu}_{j}$ & $\begin{array}{l}\text { Mean survival at } \\
\text { high temperature in } \\
\text { days }\end{array}$ & 3 & 3 & 3 & 3 & $\begin{array}{l}\text { Unpublished } \\
\text { data }\end{array}$ \\
\hline $\bar{\mu}_{j}$ & $\begin{array}{l}\text { Mean survival at } \\
\text { low temperature in } \\
\text { days }\end{array}$ & 25 & 25 & 25 & 25 & $\begin{array}{l}\text { Unpublished } \\
\text { data }\end{array}$ \\
\hline$\beta_{j}^{*}$ & $\begin{array}{l}\text { Mean egg produc- } \\
\text { tion rate }\end{array}$ & & & & 2.1 & $\begin{array}{l}\text { Unpublished } \\
\text { data }\end{array}$ \\
\hline$T h_{j}^{\mu}$ & $\begin{array}{l}\text { Higher temperature } \\
\text { tolerance in Celsius }\end{array}$ & 32 & 32 & 32 & 32 & $\begin{array}{l}\text { Unpublished } \\
\text { data }\end{array}$ \\
\hline$T l_{j}^{\mu}$ & $\begin{array}{l}\text { Lower temperature } \\
\text { tolerance in Celsius }\end{array}$ & -7 & -7 & -15 & -15 & $\begin{array}{l}\text { Unpublished } \\
\text { data }\end{array}$ \\
\hline$T h_{j}^{g}$ & $\begin{array}{l}\text { Higher temperature } \\
\text { tolerance in Celsius }\end{array}$ & 30 & 30 & 30 & 30 & $\begin{array}{l}\text { Unpublished } \\
\text { data }\end{array}$ \\
\hline$T h^{\beta}$ & $\begin{array}{l}\text { Higher temperature } \\
\text { tolerance in Celsius }\end{array}$ & 30 & 30 & 30 & 30 & $\begin{array}{l}\text { Unpublished } \\
\text { data }\end{array}$ \\
\hline$T l^{\beta}$ & $\begin{array}{l}\text { Lower temperature } \\
\text { tolerance in Celsius }\end{array}$ & 30 & 30 & 30 & 30 & $\begin{array}{l}\text { Unpublished } \\
\text { data }\end{array}$ \\
\hline$\hat{g}_{l}$ & $\begin{array}{l}\text { Maximum larva in- } \\
\text { trastadial transition } \\
\text { rate }\end{array}$ & 100 & 100 & 100 & 100 & $\begin{array}{l}\text { Unpublished } \\
\text { data }\end{array}$ \\
\hline \multirow[t]{2}{*}{$\hat{g}_{l}$} & \multirow{2}{*}{$\begin{array}{l}\text { Maximum larva in- } \\
\text { trastadial transition } \\
\text { rate }\end{array}$} & \multirow[t]{2}{*}{100} & 100 & \multirow[t]{2}{*}{100} & \multirow[t]{2}{*}{100} & \multirow[t]{2}{*}{$\begin{array}{l}\text { Unpublished } \\
\text { data }\end{array}$} \\
\hline & & & 8 & & & \\
\hline
\end{tabular}




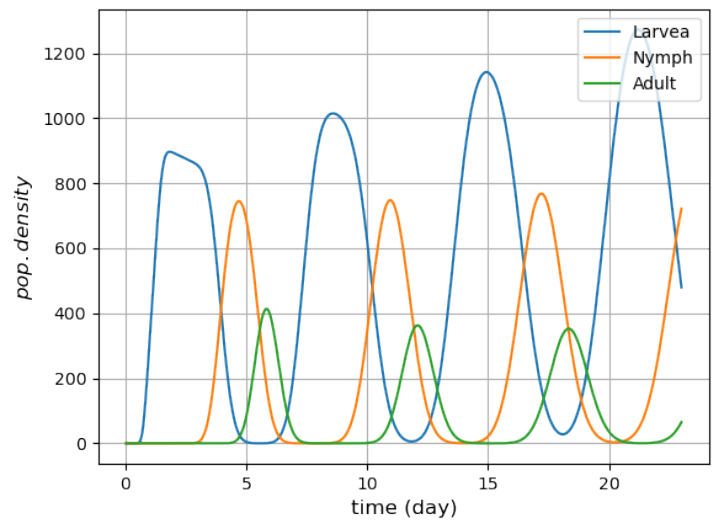

Figure 3: Larva, nymph and adult population densities

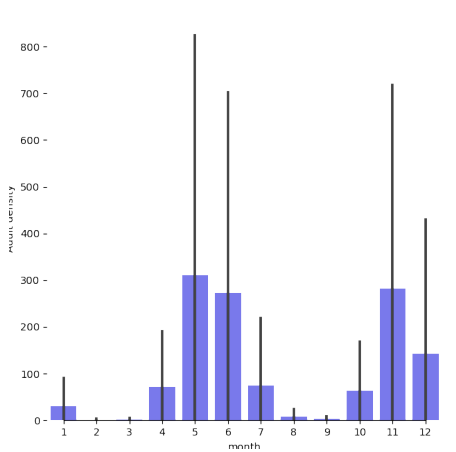

(a) Nymph

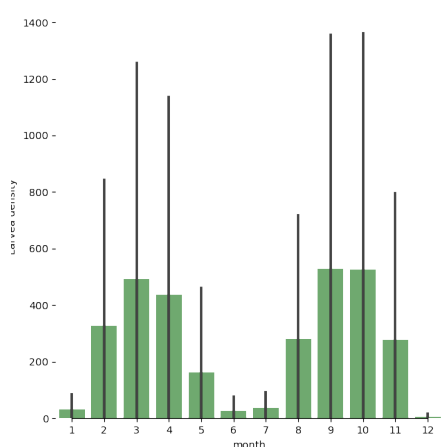

(b) Larvea

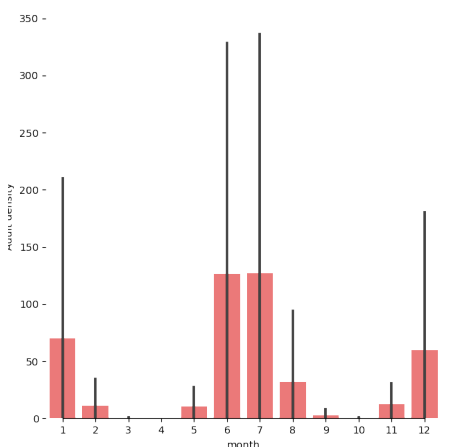

(c) Adult

Figure 4: Larva, nymph and adult population densities by size

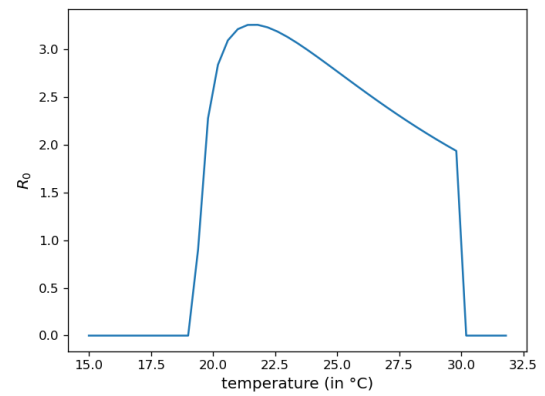

(a) $R_{0}$

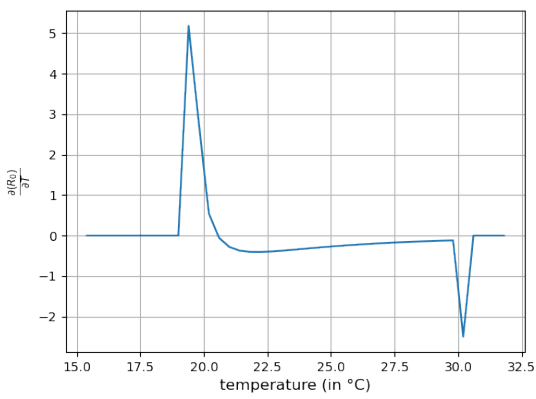

(b) Sensitive analysis $R_{0}$

Figure 5: The basic reproduction number $R_{0}$ by temperature 


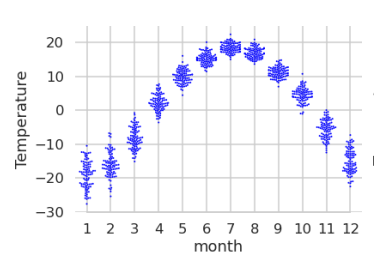

(a) CA

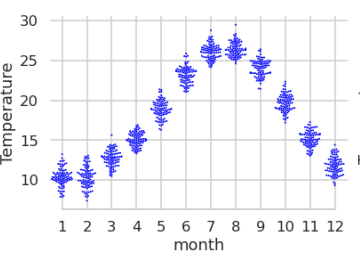

(b) $\mathrm{TN}$

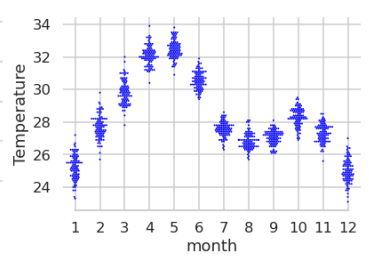

(c) SN

Figure 6: Monthly temperature distribution in the period $1904-1995$ for Canada (CA), Tunisia (TN) and Senegal (SN)

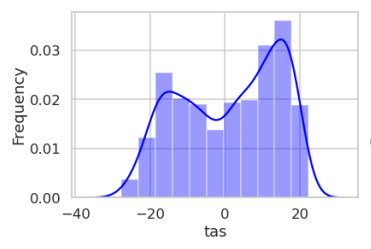

(a) $\mathrm{CA}$

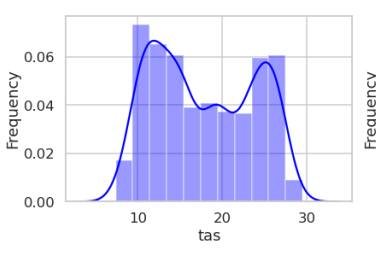

(b) $\mathrm{TN}$

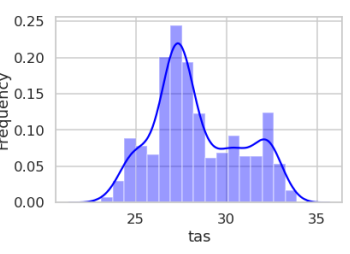

(c) SN

Figure 7: Temperature distribution in the period $1904-1995$ and the period $1995-$ 2005 ,respectively for Canada (CA), Tunisia (TN) and Senegal (SN)

data from 1904 to 1995 (see figure 6). The physiological parameters of ticks have been set to the same values for three different climatic environments, except for diapause temperature that has been set about the country's annual temperature distribution.

Canada is characterized by cold and dry winters and warm (i.e. $T=20^{\circ} \mathrm{C}$ ) summers (see figures 6a and 7a). The temperature between April to October is positive and does not exceed $20^{\circ} \mathrm{C}$. The temperature decreases to $-20^{\circ} \mathrm{C}$ to $-30^{\circ} \mathrm{C}$ in January (see figure 6a).

Tunisia is characterized by a Mediterranean climate, mild (i.e. $10{ }^{\circ} \mathrm{C}$ ) and wet winters and hot (i.e. $30^{\circ} \mathrm{C}$ ) and dry summers (see figures 6a and 7a).

Senegal is characterized by a dry period and a wet period (see figures $6 a$ and 7a). The wet periods (July and August) are warm (Temperature $28^{\circ} \mathrm{C}$ ) and the dry periods (March and April) are hot (see figure 6a).

Short-term simulations: First, we simulated the evolution of life cycles over 3 years in Tunisia and Senegal from June 2002 to June 2005. Given the extreme temperatures, the life cycle in Canada extends over 2 years, so we simulated the life cycle over 10 years from June 1995 to June 2005.

Our model predicts a significant difference in nymph and adult population 195 density variations between the three countries (see figure 8). The amplitude of seasonal variations is observed in the Mediterranean climate, where the population density in Tunisia rises from 0 in winter to 2000 in summer (see figure $8 \mathrm{~b})$. As we move further south or north, the amplitude decreases; In Canada, 


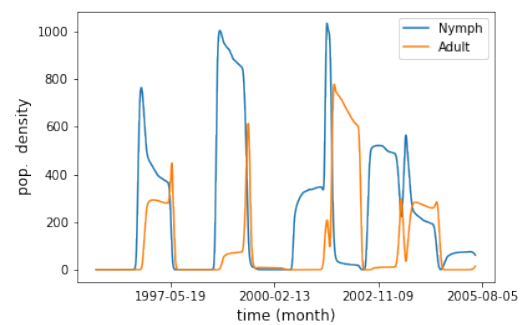

(a) CA-1995 - 2005

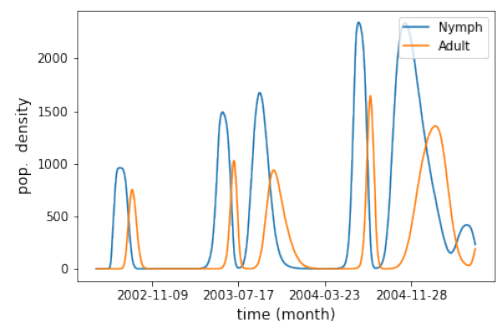

(b) TN-1995- 2005

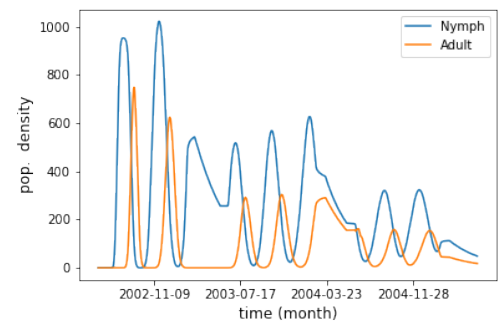

(c) $\mathrm{SN}-1995-2005$

Figure 8: Total population density by countries and for the periods $1991-2015$

we observe that seasonal fluctuations in adult density between 0 in winter and population density satisfies a large set of differential equations. Our model is 


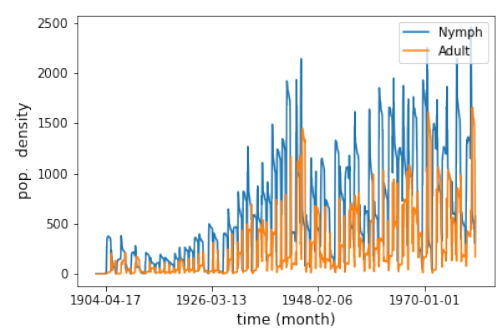

(a) CA-1902 - 2005

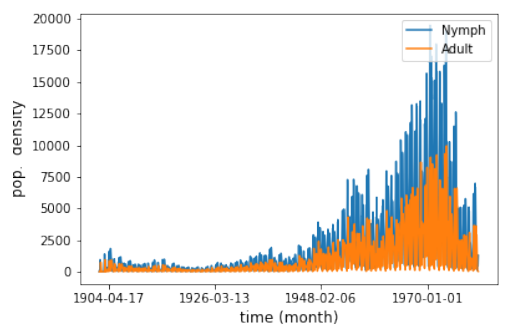

(b) TN-1902-2005

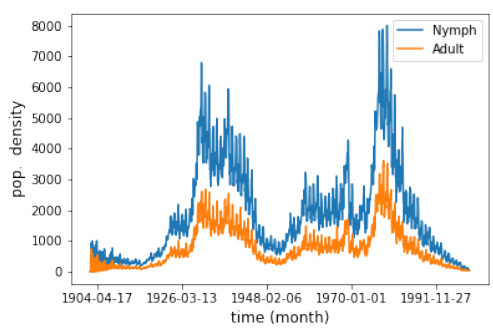

(c) $\mathrm{SN}-1902-2005$

Figure 9: Total population density by countries and for the periods $1902-2005$

located at an intermediate level between the existing models assuming that physiological structuring is represented by a finite number of classes often small $[30,7,14]$ and the continuous PDE models $[18,36]$.

Physiological models were developed by [18] where authors analyzed examples of a partial differential equation with physiological states belonged to an infinite non-countable set. However, the development of corresponding model equations is complex and, in many cases, does not allow displaying demographic parameters such as $R_{0}$. Our approach succeeded in analytically exhibiting it.

Seasonality variation is particularly important to an organism with an annual life cycle. Analyzing the demography of these species is complicated as two time scales are involved, firstly within the year when the life cycle occurs and secondly, between years when reproduction and death occur. In several cases, the duration 240 of the life cycle periods is directly related to temperature. The development rate evaluation methods require the calculation of the development fraction achieved on each day, a value depending on the daily temperature [7]. This calculation introduces complexity in the mathematical analysis. The originality of our model lies in considering temperature-dependent intrastate transition rate. This coupling approach enables us to solve the scale coupling problem without using two-time scales and/or delay to account for tick diapause, and therefore, highlight fluctuations in population density in correlation with seasonality.

We showed that seasonality is the main factor for the synchronization of different physiological classes (nymphs and adults) in the population. Indeed, we notice that in three climate conditions climates, both physiological stages are mainly asynchronous with a slight overlapping indicating the ongoing moulting process. We showed that seasonality is the main factor for the synchronization of different physiological classes (larvae, nymphs, and adults) in the population. Indeed, we notice that in cold climates, such as in the case of Canada, nymphs and adults stages are separated. Conversely, in Senegal where seasonal variations are almost nonexistent, due to low annual temperature fluctuation, activity periods for both tick stages are more clearly coexisting within the year. Tunisia, due to its Mediterranean climate, represents an intermediate context, where, according to our modeling approach, the three $H$. scupense stages whilst having 
separated peaks, continue to show a clear overlapping, which however appears more pronounced than recorded under field conditions $[1,8]$.

Furthermore, according to our model, at constant temperature, larvae are predicted to be present along the year at different densities and adults are expected to be present over a long period exceeding their usual activity season during summer.

We notice that, whatever the climate, all the physiological parameters of the life cycle of the ticks in our model are the same, except the lower bound of the temperature tolerance. This adaptation to the climate through a lower bound of the temperature tolerance could explain why some tick species are present in extreme climates (e.g. Haemaphysalis longicornis,I.ricinus) [39, 13]. We show that this adaptation can be done only on low values of developmental rate.

When applied to assess population dynamics, our model revealed, globally over the period 1995 - 2015 comparatively to the beginning of the century 1901 - 1925, a clear trend for increased tick densities in Canada with I. cookie and in Tunisia with $H$. scupense. Accordingly, temperature overall changes from $1901-25$ to $1995-2015$ are potentially more favorable to tick development in Canada and Tunisia, suggesting then I. cookie and H. scupense populations, may continue to expand if this dynamic of climatic change is maintained and if other tick populations regulating factors are not coming into play. Contrasting 280 results were obtained in Senegal with the tick species $A$. variegatum. In fact, our simulations are showing that the $A$. variegatum population had known a clear two peaks during the last century, with a significant decrease in population densities between $1995-2005$.

One of the advantages of our model is its incremental capacity to be extended to incorporate more accurate data on tick biology, and in particular survival of free stages to biotic and abiotic factors, if a more precise prospective analysis is required for a given tick species under specific environmental contexts. Furthermore, this advantage could allow its application to model pathogen transmission dynamics by predicting risk factors for vector-borne pathogens transmission and 290 in particular vector abundance and seasonality, and by expressing the pathogen basic reproductive rate $R_{0}$ according to (or as a function?) to $R_{0}$ of the vector tick population.

In the current model, we only consider one climatic factor; temperature. Various biotic and abiotic elements interact continuously (e.g., relative humidity, 295 hazardous chemicals, photoperiod, parasitism, etc.). As a result, populations can exhibit shifting responses to the environment, and some life stages will be more sensitive to these factors than others. For instance, a further study that examines a more explicit relationship between temperature and bioenergetic budgets dynamics, specifically in moulting ticks, will be required to establish a thorough understanding of the consequences of climate change on ticks' life cycle. 


\section{Funding}

The work was funded by the laboratory of "Laboratoire d'epidemiologie des infections enzootiques des herbivores en Tunisie: application a la lutte" (LR16AGR01) (Ministere de l'enseignement supérieur et de la recherche scientifique, Tunisie), the laboratory of "Bioinformatique, biomathematique et biostatistique" (LR16IPT09) (Ministere de l'enseignement supérieur et de la recherche scientifique, Tunisie) and was partly supported by the CGIAR Research Program on Livestock. The Department de Mathematiques of l'UADB provides travel grant that contribute to realize this work. SBM and PIN acknowledge the Director of UFR SATIC and Prof.Henda el Fekih who facilitate their collaboration and scientific visits.

\section{Acknowledgment}

We thank Prof. Mohamed Gharbi for his valuable comments and assistance.

\section{Bibliography}

\section{References}

[1] A. Bouattour, M. A. Darghouth, L. B. Miled, L. Ben Miled, and L. BenMiled. Cattle infestation by Hyalomma ticks and prevalence of Theileria in $\mathrm{H}$. detritum species in Tunisia. Veterinary Parasitology, 65(3-4):233-245, 1996.

[2] J. S. Brownstein, T. R. Holford, and D. Fish. Effect of climate change on lyme disease risk in North America. EcoHealth, 2(1):38-46, 2005. ISSN 16129202. doi: 10.1007/s10393-004-0139-x.

[3] M. A. Darghouth, M. Gharbi, E. Khlij, M. Ben Hamouda, and D. Gabiña. Impact of the environment mutations on diseases: case of sheep production in Tunisia. In E. Khlij, M. Ben Hamouda, and D. Gabiña, editors, Séminaire International sur les "Mutations des systèmes d'élevage des ovins et perspectives de leur durabilité", Hammamet, Tunisia, 22 et 23 octobre 2008., number 97, pages 41-48, Montpellier, 2011. Mediterranean agronomic Institute.

[4] A. ELGhali and S. M. Hassan. Life cycle of the camel tick Hyalomma dromedarii (Acari: Ixodidae) under field conditions in Northern Sudan. Veterinary Parasitology, 174(3-4):305-312, 2010. ISSN 03044017. doi: 10.1016/j.vetpar.2010.08.028.

[5] A. Estrada-Pena and J. M. Venzal. Climate niches of tick species in the Mediterranean region: Modeling of occurrence data, distributional constraints, and impact of climate change. Journal Of Medical Entomology, 44:1130-1138, 2007. 
[6] A. Estrada-Peña, J. S. Gray, O. Kahl, R. S. Lane, and A. M. Nijhof. Research on the ecology of ticks and tick-borne pathogens-methodological principles and caveats, aug 2013. ISSN 22352988.

[7] G. Gettinby, W. P. Gardiner, J. S. Gray, G. Gettinby, and J. S. Gray. Models based on weather for the development phases of the sheep tick, ixodes ricinus L. Veterinary parasitology, 9(1932):75-86, 1981. ISSN 03044017. doi: 10.1016/0304-4017(81)90009-1.

[8] M. Gharbi, M. A. Darghouth, K. Elati, A. Al-Hosary, O. Ayadi, D. A. Salih, A. M. E. Hussein, M. Mhadhbi, M. K. Khbou, S. M. Hassan, O. Isaiah, L. S. Ahmed, and J. Ahmed. Current status of tropical theileriosis in Northern Africa: a review of recent epidemiological investigations and implications for control. Transboundary and Emerging Diseases, in press, 2020.

[9] M. Ghosh and A. Pugliese. Seasonal population dynamics of ticks, and its influence on infection transmission: a semi-discrete approach. Bulletin of Mathematical Biology, 66(6):1659-1684, 2004. ISSN 0092-8240. doi: 10.1016/j.bulm.2004.03.007.

[10] M. Ghosh, P. Chandra, P. Sinha, and J. B. Shukla. Modelling the spread of carrier-dependent infectious diseases with environmental effect. Applied Mathematics And Computation, 152(2):385-402, 2004.

[11] P. A. Hancock, R. Brackley, and S. C. Palmer. Modelling the effect of temperature variation on the seasonal dynamics of Ixodes ricinus tick populations. International Journal for Parasitology, 41(5):513-522, apr 2011. ISSN 00207519. doi: 10.1016/j.ijpara.2010.12.012. URL https: //pubmed.ncbi.nlm.nih.gov/21295037/.

[12] M. P. Hassell, R. M. May, S. W. Pacala, and P. L. Chesson. The persistence of host-parasitoid associations in patchy environments I. A general criterion. American Naturalist, 138(3):568-583, sep 1991. ISSN 00030147. doi: 10. $1086 / 285235$.

[13] C. Herrmann and L. Gern. Survival of Ixodes ricinus (Acari: Ixodidae) nymphs under cold conditions is negatively influenced by frequent temperature variations. Ticks and Tick-borne Diseases, 4(5):445-451, sep 2013. ISSN 1877959X. doi: 10.1016/j.ttbdis.2013.05.002. URL https://pubmed.ncbi.nlm.nih.gov/23850119/.

[14] D. King, G. Gettinby, and R. M. Newson. A Climate-based Model for the Development of the Ixodid Tick, Rhipicephalus appendiculatus in East Coast Fever Zones. Veterinary Parasitology, 29(1):41-51, 1988. ISSN 03044017. doi: 10.1016/0304-4017(88)90006-4.

[15] S. S. A. L. M. Kooijman. Dynamic Energy Budget theory for metabolic organisation. Cambridge University Press, Cambridge, New York, Port Chester, Melbourne, Sydney, third edition, 2010. ISBN 9780521131919. 
[16] A. D. Lees and A. Milne. The seasonal and diurnal activities of individual sheep ticks (ixodes ricinusl.). Parasitology, 41(3-4):189-208, dec 1951. ISSN 14698161. doi: 10.1017/S0031182000084031.

[17] Y. Lou and J. Wu. Modeling Lyme disease transmission. Infectious Disease Modelling, 2(2):229-243, may 2017. ISSN 24680427. doi: 10.1016/j.idm. 2017.05.002.

[18] J. A. J. Metz and O. Diekmann. The dynamics of physiologically structured populations, volume 68. Springer, 1986.

[19] H. G. Mwambi. Ticks and tick borne diseases in Africa: a disease transmission model. Mathematical Medicine and Biology, (2002):275-292, 2002.

[20] H. G. Mwambi, J. Baumgartner, K. P. Hadeler, and J. Baumgrtner. Ticks and tick-borne diseases: a vector-host interaction model for the brown ear tick (Rhipicephalus appendiculatus). Statistical Methods in Medical Research, 9(3):279-301, jun 2000. ISSN 0962-2802. doi: 10.1177/ 096228020000900307.

[21] S. Nava. An overview of systematics and evolution of ticks. Frontiers in Bioscience, Volume(14):2857, 2009. doi: 10.2741/3418.

[22] R. Norman, R. G. Bowers, M. Begon, and P. J. Hudson. Persistence of tick-borne virus in the presence of multiple host species: tick reservoirs and parasite mediated competition. Journal of Theoretical Biology, 200(1): 111-118, sep 1999. doi: 10.1006/jtbi.1999.0982.

[23] R. A. Norman, A. J. Worton, and L. Gilbert. Past and future perspectives on mathematical models of tick-borne pathogens. Parasitology, 143(7): 850-859, jun 2016. ISSN 14698161. doi: 10.1017/S0031182015001523.

[24] C. J. O'Callaghan, G. F. Medley, T. F. Peter, and B. D. Perry. Investigating the epidemiology of heartwater (Cowdria ruminantium infection) by means of a transmission dynamics model. Water Res., 117:49-61, 1998.

[25] N. H. Ogden, M. Bigras-Poulin, C. J. O'Callaghan, I. K. Barker, L. R. Lindsay, A. Maarouf, K. E. Smoyer-Tomic, D. Waltner-Toews, and D. Charron. A dynamic population model to investigate effects of climate on geographic range and seasonality of the tick Ixodes scapularis. International journal for parasitology, 35(4):375-389, 2005. ISSN 00207519. doi: 10.1016/j.ijpara.2004.12.013.

[26] N. H. Ogden, M. Bigras-Poulin, C. J. O'callaghan, I. K. Barker, K. Kurtenbach, L. R. Lindsay, and D. F. Charron. Vector seasonality, host infection dynamics and fitness of pathogens transmitted by the tick Ixodes scapularis. Parasitology, 134(Pt 2):209-227, 2007. doi: 10.1017/S0031182006001417. 
[27] J. L. Perret, P. M. Guerin, P. A. Diehl, M. Vlimant, and L. Gern. Darkness induces mobility, and saturation deficit limits questing duration, in the tick Ixodes ricinus. Journal of Experimental Biology, 206(11):1809-1815, jun 2003. ISSN 00220949. doi: 10.1242/jeb.00345.

[28] J.-L. Perret, O. Rais, and L. Gern. Influence of Climate on the Proportion of Ixodes ricinus Nymphs and Adults Questing in a Tick Population. Journal of Medical Entomology, 41(3):361-365, may 2009. ISSN 00222585. doi: 10.1603/0022-2585-41.3.361.

[29] S. E. Randolph. Abiotic and biotic determinants of the seasonal dynamics of the tick Rhipicephalus appendiculatus in South Africa. Medical and Veterinary Entomology, 11(1):25-37, jan 1997. ISSN 0269-283X. doi: 10. 1111/j.1365-2915.1997.tb00286.x.

[30] S. E. Randolph. Tick-borne disease systems emerge from the shadows: the beauty lies in molecular detail, the message in epidemiology. Parasitology, 136(12):1403-1413, oct 2009. ISSN 0031-1820. doi: $10.1017 /$ S0031182009005782.

[31] S. E. Randolph and D. J. Rogers. A generic population model for the African tick Rhipicephalus appendiculatus. Parasitology, 115 ( Pt 3:265-79, sep 1997. ISSN 0031-1820.

[32] S. E. Randolph, R. M. Green, A. N. Hoodless, and M. F. Peacey. An empirical quantitative framework for the seasonal population dynamics of the tick Ixodes ricinus. International Journal for Parasitology, 32(8): 979-989, jul 2002. ISSN 0020-7519. doi: S0020-7519(02)00030-9.

[33] R. Rosà and A. Pugliese. Effects of tick population dynamics and host densities on the persistence of tick-borne infections. Mathematical biosciences, 208(1):216-240, 2007. ISSN 0025-5564. doi: 10.1016/j.mbs.2006.10.002.

[34] R. Rosà, A. Pugliese, R. Norman, and P. J. Hudson. Thresholds for disease persistence in models for tick-borne infections including non-viraemic transmission, extended feeding and tick aggregation. Journal of theoretical biology, 224(3):359-376, 2003.

[35] D. E. Sonenshine. Range expansion of tick disease vectors in north america: Implications for spread of tick-borne disease, 2018. ISSN 16604601.

[36] S. Tuljapurkar and H. Caswell. Structured-population models in marine, terrestrial, and freshwater systems. Kluwer Academic Pub, 1997.

[37] . University of East Anglia Climatic Research Unit, H. I., and J. PD. CRU TS4.03: Climatic Research Unit (CRU) Time-Series (TS) Version 4.03 of High Resolution Gridded Data of Month-by-month Variation in Climate (Jan. 1901- Dec. 2018).. Centre for Environmental Data Analysis, 22 January 2020., 2020. URL http://dx.doi.org/10.5285/ 10d3e3640f004c578403419aac167d82. 
[38] A. R. Walker, A. Bouattor, J. L. Camicas, A. Estrada-Pena, I. G. Horak, A. A. Latiff, R. G. Pegram, P. M. Preston, a. R. Walker, A. Bouattour, J.-L. J. Camicas, A. Estrada-peña, I. G. Horak, A. A. Latif, R. G. Pegram, and P. M. Preston. Ticks of Domestic Animals in Africa: a Guide to Identification of Species. Number JANUARY. 2003. ISBN 095451730X.

[39] Z. J. Yu, Y. L. Lu, X. L. Yang, J. Chen, H. Wang, D. Wang, and J. Z. Liu. Cold hardiness and biochemical response to low temperature of the unfed bush tick Haemaphysalis longicornis (Acari: Ixodidae). Parasites and Vectors, 7(1):1-7, jul 2014. ISSN 17563305. doi: 10.1186/1756-3305-7-346. URL http://www.parasitesandvectors. com/content/7/1/346. 